\title{
ESCRITURA Y ORALIDAD EN EL DESIERTO PRODIGIOSO $Y$ EL PRODIGIO DEL DESIERTO (CIRCA 1650), NOVELA DE PEDRO DE SOLÍS Y VALENZUELA
}

\author{
POR \\ Flor María Rodríguez-Arenas \\ Columbia University
}

En los territorios de Hispanoamérica durante la época colonial, la complejidad y la ambigüedad estuvieron presentes en todos los aspectos diarios de la vida. De la misma manera en que realidad y ficción, y oralidad y escritura estaban imbricadas en la vida y en los actos de conquistadores y colonizadores corno: Colón, Cortés, Bernal Díaz del Castillo, Cabeza de Vaca, etc., durante los siglos coloniales se mantuvo en estos territorios la dual ambigüedad entre la prohibición contra la escritura de prosa de ficción y su producción; como también, la coexistencia y subversión mutua entre la oralidad de las culturas indígenas y la de los iletrados europeos y la literariedad importada y entronizada por los europeos a través de la escritura alfabética.

La existencia de novelas coloniales hispanoamericanas se viene estudiando desde hace unas décadas. ${ }^{1}$ Para la comprensión y el estudio de estos textos específicos, se debe recordar que las concepciones sobre lo que hoy se considera novela y literatura comenzaron a prevalecer a partir de la Ilustración. La noción de lo literario no estaba confinado a lo "creativo", como se percibe en el presente; por eso, los autores anteriores a esta época se consideraban a sí mismos simplemente como "escritores", y elaboraran textos con características de novela, de relato histórico, de composición poética, etc. De ahí que, los

\footnotetext{
${ }^{1}$ Algunos estudios sobre novelas coloniales son: Roberto Esquenazi Mayo. "Raíces de la novela hispanoamericana". Studi di Letteratura Ispanoamericana. II (1969) 115-120. Pablo Neruda, "Una novela: [Historia tragicómica de don Enrique de Castro]". Ercilla (Santiago, 1772/4-10 de junio de 1969). Reproducida en Para nacer he nacido. (Barcelona: Seix Barral, 1977) 198-200. Francisco Sánchez Castañer, "La obra literaria de Juan Palafox y Mendoza, escritor hispanoamericano". Actas del Tercer Congreso Internacional de Hispanistas. (México: El Colegio de México, 1970) 787793. Juan José García Gómez, "Pablo de Olavide: primer novelista en Hispanoamérica". Humanitas 16 (Nuevo León, 1975) 231-246. Luis Leal, "El Siglo de oro de Balbuena: primera novela americana". Kentucky Romance Quarterly 23.3 (1976) 327-334. Martin Lienhard, "Una novela hispanoamericana en 1586 (José de Acosta, La peregrinación de Bartolomé Lorenzo)". Homenaje de los hispanistas de Suiza: a Ramón Sugranyes de Franch. (Montserrat: Publicaciones de L'Abadia de Mortserrat, 1982) 175-187. Cedomil Goiç, "Novela hispanoamericana colonial". Historia de la literatura hispanoamericana: época colonial. (Madrid: Cátedra, 1982) 369-405. Lucrecio Pérez Blanco, "Novela ilustrada y desmitificación de América". Cuadernos Americanos XLIV.5 (septiembreoctubre, 1982) 176-195. Manuel Briceño Jáuregui, Estudio histórico-crítico de El desierto prodigioso y el prodigio del desierto de don Pedro de Solís y Valenzuela. (Bogotá: Instituto Caro y Cuervo, 1983).
} 
escritos que se designan hoy como novelas coloniales hispanoamericanas posean elementos de esos otros géneros.

Aún más, en la misma forma en que Terry Eagleton (17) afirma que los escritores del siglo XVIII de la Gran Bretaña desconocían conceptos como "respuesta personal" o "imaginación única", que se relacionan intrínsecamente hoy con lo que se considera literario, esas nociones tampoco tenían sentido para Pedro de Solís y Valenzuela, Francisco Bramón o Pablo de Olavide, algunos de los "novelistas" del periodo colonial.

Además, la novela colonial hispanoamericana predieciochesca escrita por criollos surge en una época de crisis para la novela española. Es decir, junto a las características ya mencionadas, añade a su estructura el hecho de carecer de patrones que imitar; pues, las formas novelescas que se habían establecido en España desde mediados del siglo XVI, hasta antes de la mitad del XVII habían entrado casi en plena disolución, haciendo que no hubiera una producción narrativa fuerte que se mostrara como continuación de lo elaborado durante la centuria anterior.

Ese fenómeno de la novela española ha recibido diversas explicaciones; tal vez, la más cercana al origen del problema sea la confusión que se produjo entre estructuras del mundo comentado y las del mundo narrado (Weinrich 61-94), causadas por tratadistas y retóricos de la época (López Grijera). La cual habría producido una creciente y progresiva intercalación dentro de la narrativa, de estructuras pertenecientes a deliberaciones, monólogos, descripciones, cartas, comentarios, discusiones, etc., provocando estatismo y pasividad en lo relatado.

Por eso, ninguno de los textos predieciochescos considerados novelas coloniales hispanoamericanas presenta un relato que se circunscriba fielmente a uno solo de los tipos novelescos que imperaron en España hasta antes de la década del treinta en el siglo XVII, sino que ofrecen una fusión de varios de ellos, disfrazados de tratados ascético-religiosos para, tal vez, tratar de evadir o quizá intentar conformarse a las prohibiciones impuestas por la Iglesia e impulsadas duramente por la Inquisición contra la producción de prosa de ficción. ${ }^{2}$

Además, deben tenerse en cuenta los procesos de conocimiento o comprensión intelectual y de memoria que surgieron y desarrollaron las culturas indígenas y europeas que entraron en conflicto en esos territorios; procesos que se hallan latentes en diversos grados en la estructuración discursiva de esos textos, y que se hacen más complejos cuando la oralidad y la literariedad se hallan en estrecha relación, como ocurrió durante la época colonial.

\footnotetext{
${ }^{2}$ Se consideran novelas coloniales: Peregrinación de Bartolomé Lorenzo (1586) de José de Acosta; Siglo de oro en las selvas de Erifile (publicada en 1608, escrita entre 1580-1585) de Bernardo de Balbuena; La historia tragicómica de don Enrique de Castro (1617) de Francisco Loubayssin de la Marca; Los sirgueros de la virgen (1620) de Francisco de Bramón; El pastor de Nochebuena (1644) de Juan Palafox y Mendoza; Sueño de sueños (1788) de José Mariano Acosta; La portentosa vida de la muerte (1792) de Joaquín de Bolaños; el grupo de novelas escritas por Pablo de Olavide (17971803); siete de ellas publicadas póstumamente en 1828, etc.

La temática religiosa y la cosmovisión barroca de sentido moralizante y ascética, que caracterizan la obra de Solís y Valenzuela, se manifiestan con variaciones, debidas al racionalismo y al espíritu ilustrado dieciochesco, en la mayoría de las obras ya mencionadas, posteriores al Desierto prodigioso yel prodigio del desierto.
} 
Sobre características culturales de este tipo, se han efectuado diversos estudios, que se han enfocado en el fenómeno de la hegemonía de culturas grafocéntricas sobre culturas autóctonas con sistemas gráficos o de notación diferentes, o de las particularidades con que el proceso fue marcando las culturas subyugadas en su adopción forzada de la escritura: Goody (1977, 1987), Ong (1982). Recientemente otros análisis tratan de mostrar los dos polos de la situación: las funciones que cumplen la oralidad y la literariedad y la forma como ellas afectan las sociedades: Olson y Torrance, editores (1991); Digges y Rappaport (1992). ${ }^{3}$ Anticipándose a estos últimos estudios, aplicada exclusivamente a la presencia ineludible de la oralidad como fundamento de literaturas alternativas latinoamericanas, se encuentra la sugestiva obra de Lienhard (1990).

El texto de uno de los novelistas coloniales hispanoamericanos, el clérigo neogranadino Pedro de Solís y Valenzuela, nacido en Santa Fe de Bogotá (1624-1711), ${ }^{4}$ presenta un claro ejemplo de coexistencia de los aspectos ambiguos antes mencionados para los textos coloniales. Su obra, El desierto prodigioso y el prodigio del desierto, ${ }^{5}$ escrita hacia 1650 , además de ser producida en el momento histórico de disolución de las formas novelescas españolas, es una obra de ficción, elaborada no por un letrado seglar sino por un religioso, quien a su vez fue miembro de los Tribunales de la Inquisición. La estructura de su narrativa presenta: imbricación de realidad y ficción, coexistencia y confluencia de escritura y oralidad a nivel de su historia, y subversión de la oralidad en la escritura a nivel de su discurso.

La conocida aseveración de Clark y Holquist, sobre la visión bakhtiniana de la novela, contribuye a explicar la percepción sobre este texto novelístico colonial hispanoamericano:

${ }^{3}$ Estas investigadoras examinan el fenómeno desde el interior de la cultura avasallada, contextualizándolo dentro de la cultura hegemónica para comprender las profundas diferencias de los procesos de conocimiento y comprensión entre las percepciones enfrentadas.

${ }^{4}$ Pedro Félix Solís y Valenzuela nació el 10 de mayo de 1624; fue uno de los siete hijos de Pedro Fernández de Valenzuela y Juana Vásquez de Solís. Estudió, en el colegio-seminario de San Bartolomé, el bachillerato, cuando su hermano mayor, Fernando, se hallaba en el mismo establecimiento terminando el doctorado en teología. Ordenado sacerdote, se desempeñó como capellán en Usaquén, Acataima, Tocaima, Soacha, Bosa, Anolaima, Calandaima, la Calera, Guadalupe y Monserrate. En este oficio actuaba como administrador, patrono o albacea para asegurar con los productos de fincas los gastos de la celebración de misas, según la intención del fundador de la capellanía. Esas ocupaciones le proporcionaron incontables pleitos legales con los herederos de las tierras, quienes no cumplían con los pagos de sus obligaciones por morosidad o por pobreza. En 1693 hizo testamento y falleció a la edad de 87 años, el 27 de julio de 1711 en su ciudad natal. Su inclinación literaria lo llevó a producir obras; algunas desaparecidas: "Retórica cristiana", "El despertador de la vida", "Asombros de la muerte", "El panal de Sansón"; otras conservadas: La Fénix cartuxana: Vida del gloriossísimo Patriarca San Bruno (1647), Epitome breve de la viday muerte del ilustrísimo doctor don Bernardino de Almansa, Panegírico sagrado: en alabanza del serafin de las soledades, San Bruno (Lima, 1646; Madrid, 1647) y El desierto prodigioso y el prodigio del Desierto.

${ }_{5}^{5}$ Obra que editó, entre 1977-1984, el Instituto Caro y Cuervo. El manuscrito de El desierto se conservaba en la Fundación Lázaro Galdeano de Madrid. Este manuscrito, inicialmente era el único que se conocía, consta de XXII mansiones. En 1970 se descubrió otro en Medellín, Colombia, que sólo posee III mansiones y presenta importantes variantes fictivas y de extensión con respecto al de Madrid; ambos están escritos por la mano de don Pedro. 
Bakhtin asigna el término "novela" a cualquier forma de expresión dentro de un sistema literario dado, que revela los límites de ese sistema como inadecuado, impuesto o arbitrario. Los sistemas literarios están compuestos de cánones, y la novela es fundamentalmente anticanónica. No permite el monologismo genérico. Insiste en el diálogo con esos textos que están excluidos de tal definición $(1984,276)^{6}$

Estas aserciones ayudan a contextualizar la ficción colonial dentro del género ${ }^{7}$ novelístico, haciendo más accesible un acercamiento a la pluralidad de discursos que el multifacético mundo narrativo creado por Solís y Valenzuela presenta desde su apertura.

Ya desde el título, El desierto prodigioso y el prodigio del desierto se observa un juego conceptista entre las palabras "desierto" y "prodigio", a través del cual se anticipa, en el nivel de la representación, no sólo el lugar donde ocurrirán los actos impulsadores de la acción sino el tipo de sucesos inesperados, milagrosos, que originarán una serie de conversiones y cambios en la vida de los personajes implicados más importantes. ${ }^{8}$

Adscribiéndola a los tipos de narrativa existentes en su momento histórico, la acción ${ }^{9}$

${ }^{6}$ Para Bakhtin la novela es una forma híbrida, por lo tanto anticanónica, representación de una diversidad de mundos que se manifiesta a través de la interacción de diferentes lenguajes, de diferentes voces de igual valor, entre las que la del autor es sólo una (Dialogic 35-39, 43-49). Junto a estas percepciones, también observa que: "El significado histórico de la novela barroca es enorme. Casi todas las categorías de la novela moderna tienen su origen en uno $u$ otro de sus aspectos. La novela barroca, heredera de todo el desarrollo precedente de la novela, y utilizando esta herencia al máximo (la novela sofística, el Amadis, la novela pastoril), fue capaz de unificar dentro de sí todos los siguientes elementos: problemática, aventura, historia, sicología, lo social; elementos que luego figurarían como categorías independientes de novela. La novela barroca llegó a ser en tiempos posteriores una enciclopedia de información de motivos novelísticos para la novela moderna [...]" (Dialogic 388).

${ }^{7}$ En este caso, género no sólo refiere a la clasificación que se hace de un texto según se adscriba con mayor o menor fidelidad a unas ciertas características formales y de contenido, sino también a la manera como el lector o el oyente percibe dicho texto (Bruner - Weisser 131).

${ }^{8}$ Ver apéndice 1, para un esquema de la estructura narrativa de $E l$ desierto.

${ }^{9}$ El argumento narra los variados prodigios que ocurren en la cueva del ermitaño Arsenio y sus alrededores, donde suceden cosas extrañas. La acción abre presentando a Andrés, quien encuentra por casualidad una cueva. Al retornar con sus amigos: Fernando, Pedro y Antonio, Andrés los persuade para buscar al dueño de aquel lugar que lo indujera a un cambio radical de vida. En su viaje, el grupo halla en el Desierto de la Candelaria al ermitaño Arsenio, quien cuenta, por instancia de los jóvenes, los sucesos de su vida disipada y la forma como había llegado a la penitencia y al arrepentimiento. El relato de su vida, lo presenta intercalado con historias de amigos y conocidos, y acontecimientos de diverso orden. A través del diálogo, el ermitaño descubre la inclinación de Andrés hacia el tipo de vida religiosa que él practica, por lo cual decide ayudarlo a recibir al hábito de los Recoletos Agustinos, llevándolo al Convento de la Candelaria. En ese lugar queda el joven; los otros integrantes del grupo prosiguen con Arsenio, quien les continúa relatando sus andanzas y las causas que lo hicieron viajar de Europa a América. En una de las paradas que efectúan, Fernando, otro de los jóvenes, confiesa al eremita el escondido deseo de hacerse cartujo, que lo ha acompañado por más de once años. Cuando los jóvenes retornan a sus casas, narrando los sucesos que impulsaron a Andrés al monasterio, la madre de Fernando y Pedro celebra la decisión, pero el padre la rechaza, prohibiéndole a sus hijos regresar por esos lugares. De esta forma, trata de evitar que alguno de 
de El desierto $^{10}$ abre con la presentación de un marco narrativo, donde se ofrecen algunos elementos estructurales de las novelas cortas italianas, ${ }^{11}$ como son: 1) el viaje y 2) la tertulia. Estas situaciones son los núcleos generadores de lo relatado. La organización estructural de $\mathrm{El}$ desierto depende de este marco y debe mucho a la novela pastoril; de la cual toma: primero, el esquema central que aglutina todos los elementos de la narración, segundo, el empleo de estaciones narrativas que coinciden en lo posible con el comienzo y el final del día, tercero, la inclusión de numerosos textos poéticos y de diversos relatos intercalados de otros géneros novelísticos, como: la hagiografía, los relatos bucólicos, las novelas bizantina y sentimental, los relatos de misterio y las anécdotas; y cuarto, el empleo de tópicos literarios, como: el lugar ameno.

El marco narrativo abarca la Mansión I (Capítulo I). En él, se encuentran cuatro jóvenes: Fernando, Pedro, Antonio y Andrés, quienes emprenden un viaje para conocer al ermitaño Arsenio, después de que Andrés hallara la cueva donde vivía el eremita. En esa gruta, localizada en un alejado y desolado sitio, se desencadenan hechos inesperados, que cambian la vida de los cuatro amigos.

El viaje de los muchachos se produce en la Mansión III, después de que Andrés se ha enfrentado a las dualidades: realidad-ilusión, escritura-oralidad, en la Mansión I, cuando perseguía con sus perros de caza a un ciervo, que evadió su persecución en una zona desértica y bastante remota. Tratando de encontrarlo, el joven halló unas borrosas y casi ilegibles inscripciones en una roca cubierta de musgo, cuyo desciframiento le permitió saber que el animal no había desaparecido por arte de magia como pensara antes, sino que había penetrado a una cueva, cuyo acceso anunciaban las borrosas palabras. Al desmontar de su caballo y penetrar al laberinto que se le presentaba como entrada, halló un recinto "que cielo forjó a su idea", donde encontró una serie de dibujos, inscripciones, versos, composiciones poéticas. Mensajes, dibujados o escritos, que, a medida que leía, descifraba y se hacían más extensos, lo movieron de la curiosidad, al asombro, al suspiro, al llanto, al arrepentimiento y finalmente a tomar la decisión de abrazar la vida religiosa. Reafirmó esa resolución cuando encontró que en aquella desértica localidad, detrás de la cueva, se hallaba un prado ameno cruzado por un cristalino río. Los descubrimientos de los diversos signos y las transformaciones que produjeron en él y hasta en los animales (perros y ciervo), que habían yacido juntos sin animadversión, lo llevaron a dudar de lo que veía y sentía, y a considerar todo aquello fantasía.

ellos abrace las órdenes religiosas, sin saber que Fernando ya posee una fuerte inclinación y que con el tiempo realizará dos intentos para entrar a la cartuja. En este punto de la narración, Pedro de Solís y Valenzuela, autor, se hace presente a través de la escritura, para revelar los misterios y ambigúedades que existen en el relato; al mismo tiempo, declara la autenticidad histórica de cada uno de los personajes: Fernando es en la vida real su hermano, quien en la vida monástica se conoce como Bruno de Valenzuela; Andrés es fray Andrés de San Nicolás y Antonio es Antonio Acero de la Cruz, conocido pintor. Enseguida presenta los datos biográficos de Fernando y la forma como éste se hizo cartujo; a la vez, ofrece la biografia de su padre y la suya propia. Don Pedro termina, prometiendo concluir su historia en una segunda parte, que al parecer nunca llevó a cabo.

${ }^{10}$ Esta será la manera como se designará la obra de Solís y Valenzuela en este estudio.

${ }^{11}$ En la novela corta italiana los acontecimientos contados dependen de un marco superior en estructura yuxtapuesta y son narrados por un grupo de personas. 
Esta ambivalencia entre la realidad y la ilusión-ficción, que siente Andrés, se repite de diversas formas a lo largo de toda la narración con: el cartapacio de papeles escrito por Arsenio, que fue sacado de la cueva por Andrés, y después, llamado por los jóvenes "el libro de las conversiones"; con la aparición de seres humanos incompletos (una mano, un hombre sin cabeza); con visiones de muertos que regresan, que hablan; con sueños que se vuelven realidad; con testimonio de hombres que visitaron el averno. El resultado que produce la unión de todas estas imágenes mentales, logra en los jóvenes un cambio de emociones y sentimientos, que los conduce a aceptar la vida religiosa como medio para alcanzar el fin que promueven todos los símbolos vistos y oídos.

El mundo relatado, ambiguo en su representación de la realidad y la ilusión, es un mundo cifrado (letras-dibujos-jeroglíficos), laberíntico (el laberinto que encripta el nombre del autor, la entrada a la cueva, el largo viaje del segundo Arsenio para encontrar el ascetismo y finalmente la vida religiosa en comunidad), que a través de distintos camuflajes (realidadficción, mentira-verdad), de dobles (los Arsenios, las visiones), de disfraces (CasimiraAscanio-Casimira ermitaña-Casimira religiosa) proyecta la rusticidad, la austeridad, el ascetismo, como bienes últimos del hombre. ${ }^{12}$ Es un mundo complejo que pide, que tiende a la simplicidad.

Pero al mismo tiempo, en otro nivel de significación, la cueva, lugar donde se originan todos los cambios con su contenido prodigioso, simboliza la entrada al mundo dominado completamente por la grafía, por el alfabeto. Mundo que queda fijado a través de la escritura, expresada con gran abundancia en los diversos rincones y superficies del recinto. Escritura que necesita de un decodificador que la interprete para que comience a ejercer la función para la cual se la creó: propagar la fe religiosa, ganando adeptos para esa forma de vida. Este decodificador-lector aporta su conocimiento social y cultural, que le permite tanto interpretar de diversas formas ese universo gráfico que se le ofrece, como llegar a aceptarlo o rechazarlo. Para evitar esta última opción, a través del grabado y el dibujo impreso en diferentes formas en la cueva, se emplea abundantemente la persuasión como arma eficaz de convencimiento. ${ }^{13}$

Cuando encuentra la cueva, a partir del desciframiento de los "mal formados caracteres", Andrés entra al mundo de lo gráfico, del dibujo con código descifrable, de la escritura, de la literariedad. Este encuentro lo alucina, llevándolo a afirmar momentáneamente que la escritura tiene poderes mágicos, como se supusiera en la Edad Media. ${ }^{14}$

\footnotetext{
${ }^{12}$ Las constantes alusiones a la vida como algo pasajero e inconsistente, la duda entre lo ilusorio y lo real, la dilucidación de la diferencia o identidad entre realidad y ficción, el reconocimiento de que la vida humana es apariencia, sueño, ficción frente a la irrefutable realidad de la muerte es muestra de un escepticismo que acentúa lo que de vano y aparencial tiene la existencia humana. Es al mismo tiempo la actitud que se adscribe al hombre del Barroco desengafiado de la realidad del mundo.

${ }^{13}$ Para el significado y la importancia durante la época, de los signos, los grabados y los dibujos encontrados en la cueva, véase Flor María Rodríguez-Arenas. "El desierto prodigioso y el prodigio del desierto o Contrarreforma y Barroco en la Nueva Granada". Actas XVIII Congreso, Instituto Internacional de Literatura Iberoamericana. "Letras coloniales: Interacción y vigencia". (México: Colegio de México [en prensa]).

14 "Cuando cualquier tipo de escritura totalmente formada, alfabética o de cualquier otra clase, hace su aparición dentro de cualquier sociedad, lo hace necesariamente al principio en sectores restringidos
} 
El universo unidireccional producido por el ermitaño Arsenio, intenta cerrarse, convertirse en comunicación pura, cuando Andrés responde no sólo con escritura a los símbolos y grafias que encuentra en las paredes de la cueva sino con "voces de la lengua" (lamentos, exclamaciones, monólogos orales). La escritura produce más escritura. Comienza la proliferación, bien por imitación, bien por asociación de ideas. Los eslabones de la cadena comunicativa se forman, se cierran, se incrementan. El signo implantado comienza a dar frutos en el sentido deseado.

A este hallazgo que Andrés hace de la escritura, sigue la difusión de los mensajes caligrafiados en el cartapacio, al ser leídos, comentados o respondidos. Mensajes que se conservan a pesar del transcurso del tiempo y de los cambios que se producen en el lugar, porque los protege la grafía plasmada en el papel. De esta forma, la palabra manuscrita se manifiesta como una potente fuerza de cambio, tanto cognitiva como social. Ya que, comienza a ejercer un poder normativo no sólo en la vida síquica sino en la física de los jóvenes.

Al evaluar finalmente el resultado producido por este mundo fundado en la letra, mundo de la literariedad, en cada uno de los diferentes personajes que se le acercan y entran en contacto con él, se puede deducir que es un mundo prodigioso, que hay que buscar e intentar comprender mediante su desciframiento; luego, se debe difundir su mensaje, porque todavía se halla remotamente aislado; por tanto, no sólo alejado sino desconocido por la mayoría de la gente. Quien no logre enterarse de ese mensaje y no pueda interpretar sus componentes, se hallará imposibilitado para penetrar sus maravillas, quedará relegado, retirado de la riqueza que encierra y del bien final que con él se obtiene.

La ideología subyacente de la voz autorial en El Desierto implica que aquéllos que pueden leer y escribir, están mejor preparados para alcanzar la salvación, que quienes son iletrados. Si la escritura permite la creación de un mundo nuevo con mensajes que al ser interpretados ayudan al logro de mejores niveles de vida, la lectura da acceso a información, a ideas, a la diversión, estimula, produce controversia, como lo demuestran las tertulias que se producen en el mundo narrativo de $E l$ desierto, a medida que se descifra el contenido de los cartapacios del ermitaño Arsenio y de la lectura de los diferentes poemas que los participantes escriben e intercambian, comentan y critican.

De esta forma, la voz autorial se hace fuerte portavoz, tanto del movimiento masivo que generó la Iglesia Católica durante la Contrarreforma ${ }^{15}$ para la recristianización de masas,

y con diversos efectos e implicaciones. La escritura a menudo se ve al principio como un instrumento de poder mágico y secreto [...] rastros de esta temprana actitud hacia la escritura pueden mostrarse etimológicamente en el inglés medieval; en él, "grammarye" o gramática, refiriéndose al conocimiento aprendido en los libros, llegó a significar: saber mágico u oculto [...]" (Ong 93). "La atribución de poderes poco menos que mágicos a la escritura permite hablar, en un sentido estricto, de su fetichización" (Lienhard 28).

15 "El Santo Tribunal de la Inquisición, las misiones, los ejercicios espirituales, el culto a reliquias y santos, la intensificación de la vida de piedad, en suma, la sobreabundancia de la presencia de los moralistas en el campo social forman parte del marco en el que se inscribe la formación de los modernos sistemas educativos. La Iglesia supo armonizar castigos ejemplares y rituales espectaculares con una pedagogía de doblegamiento de las voluntades, de fabricación de hábitos de perfección, de constitución de sujetos. Y fue a partir de esta compleja maquinaria de transformación sumamente 
como del humanismo imperante que impulsó la escritura y la consideró como una gran arma para alcanzar la salvación humana. Durante esa época, autores religiosos y seculares creían que los beneficios espirituales recaerían en aquéllos que aprendieran a leer y a escribir y quienes hicieran buen uso de la literariedad alcanzada. Literariedad que era por tanto altamente deseada, al menos en las mentes de aquéllos que ya la poseían. ${ }^{16}$

Ahora bien, la oralidad en sus distintas manifestaciones es otro aspecto importante del mundo novelesco de El desierto. La comunicación inicial que se presenta al nivel de la historia se manifiesta en la misma forma en que se produce la generación de un mensaje en una cultura oral (véase Vansina 3-27). Diseminación que se hace a través de la novedad, del beneficio comunal y del bien último que produzca. Así, el primer paso es el informe que Andrés le hace a Fernando del hallazgo de la cueva y su contenido como una primicia desconocida, que representa un descubrimiento de gran valor. Como la trascendencia del encuentro es de tal magnitud y calidad para Fernando, y el provecho que se obtiene es inmediato, los dos jóvenes deciden difundir la noticia a los demás miembros del grupo; de esta manera, las buenas nuevas se divulgan rápidamente, porque su discernimiento y aceptación implican un cambio y una mejora en la vida futura.

Al comienzo de la distribución de la noticia, Andrés actúa como testigo de lo que vio y entendió en la cueva; es decir, cuenta su experiencia personal, que requirió tanto de su atención como de la intervención de sus emociones. Esa comprensión le permitió suplir los sectores de información que se requerían para lograr el resultado que Arsenio perseguía con la estructura y disposición de los signos y símbolos gráficos y pictóricos, y con la serie de objetos contenidos en la cueva: el valor pasajero de la existencia mortal y la eternidad de la vida después de la muerte.

Después de que se han cumplido esas etapas en la historia, se procede a lo que la tradición oral normalmente efectúa: la participación de los demás integrantes del grupo en la propagación de la noticia. Por esta razón, a pesar de que los otros jóvenes confian en la veracidad de la información de Andrés, desean corroborar por sí mismos las nuevas que se les transmiten y que en parte están respaldadas por el cartapacio que el joven ha sacado del lugar.

Asimismo, en el momento en que el grupo toma la decisión de hacer el viaje para encontrar a quien ha creado ese mundo especial, entra en juego la interpretación de todos en la comprensión de la experiencia que vivió Andrés. Los cuatro amigos intercambian ideas sobre el origen de lo visto y lo vivido por uno de ellos, hacen conjeturas, toman

eficaz como los propagadores de la nueva fe contribuyeron a redefinir en sentido moderno la libertad y la cultura" (Varela 292). "La inquietud reformadora del clero iniciada por el Cardenal Cisneros durante el reinado de Felipe II hace que se traduzcan y editen diversos textos religiosos. Con ellos se crea una corriente de espiritualidad ascético-mística, por la que discurren la piedad íntima (ilustrada y afectiva) de la Devotio moderna y la ansiedad reformista del Humanismo cristiano, en la que entra el erasmismo y la proximidad al protestantismo por la insistencia en la lectura de las Escrituras y la crítica a una Iglesia oficial. Se originará así un iluminismo heterodoxo, y después un quietismo, que forjará el espíritu de la Contrarreforma en la necesidad de realizar el ideal de la vida cristiana interior dentro del seno de la Iglesia" (Prieto 524).

${ }^{16}$ Para algunos aspectos sobre la difusión de la escritura y la literariedad ver: Gellrich 1985, Cressy 1980. 
decisiones. Es decir, pasan al estado de la elaboración de una conciencia colectiva, que más tarde al ser totalmente asimilada y aceptada por todos y cada uno de los miembros, será parte de su vida cotidiana.

Andrés cuenta su experiencia por medio del recuerdo de los hechos sucedidos, de las emociones sufridas dentro de la gruta. De esta forma, el lector tiene un conocimiento más completo de la trascendencia que tuvo el contenido de las inscripciones y gráficos en él. Pues desde ese momento, el mundo del joven se concentra en los mensajes hallados, en su comprensión y en su diseminación. El exterior, todo lo que tenía que ver con su vida anterior, con el "ejercicio de las letras humanas en que gastaba el verdor de sus años, dándoles a veces los entretenimientos de la caza por intervalo y honesto ejercicio a la mocedad", deja de existir. Ahora Andrés únicamente le presta importancia a aquellos aspectos, que son esenciales a su noción de lo que anhela secretamente: abrazar la vida religiosa. De ahí que, la caza del ciervo que había emprendido, y el lugar donde quedara el animal se le borren de la mente; el joven simplemente recuerda lo que para él es substancial. De esta forma, se efectúan la selección y el reordenamiento de datos que ejerce su memoria; situación similar a los procesos dinámicos de la tradición oral de las culturas que seleccionan y transmiten sólo aquello relevante para toda la comunidad.

De igual manera, en este mismo nivel de la historia, la oralidad se manifiesta en otras formas: mediante los monólogos que sostiene Andrés en la cueva, cuando el joven responde con exaltación a los signos que va descifrando e internalizando. Luego, en las conversaciones, ${ }^{17}$ ya mencionadas, que tiene con los otros amigos, y más tarde, con los diálogos poéticos ${ }^{18}$ que se producen entre el grupo y el ermitaño Arsenio.

En este mundo narrativo, lo oral es una parte importante y esencial que sirve, al nivel de la historia, para que tres narradores representados (Arsenio, el Padre Prior y Fernando) cuenten relatos, que corresponden a distintos tipos de literatura oral y escrita, existentes en

${ }^{17}$ Conversación: "manera familiar de hablar fuera de un escenario institucional, presupone - junto con la oralidad - la simetría de roles. Cuando se "habla" en un escenario institucional —una clase, una corte de justicia, un debate público, etc.- no se "conversa", sea porque los papeles que desempeñan los interlocutores no son simétricos, [...] sea porque no se habla libremente [...] La conversación necesita de la simetría de los papeles o roles sociales de los interlocutores [...]. Un componente fundamental de la conversación [...] es el intercambio de turnos (turn-talking) [...] la conversación al igual que otras formas de interacción oral, es un proceso enmarcado entre un comienzo y un final, una apertura y un cierre. El marco de la conversación no necesariamente coincide con la introducción de un tópico y su agotamiento o con la introducción de un problema y su solución [...]. La conversación exige menos la coherencia que la conexidad (Mignolo 7-8).

18 "La forma de escritura llamada diálogo imita la conversación" (Wynne, Essay 1822) [...]. Las conversaciones escritas o diálogo no tienen el privilegio ni pueden tener las libertades y ser tan desconectadas como las conversaciones de la vida diaria [...]. En la conversación escrita se debe elegir un tema o tópico y debe desarrollarse de acuerdo a algún plan [...]. El escritor de diálogos debe atender menos a la acción y más a las partes subordinadas del drama [...] el escritor debe omitir la ostentación puesto que ésta sería tan intolerable en un discurso cuyo fin es didáctico [...] si el diálogo es una copia de la conversación diaria o familiar no debe degenerar en disertación [...]" (Mignolo 15-16). Para otros aspectos del diálogo véase: Boves Naves (1992). 
la época en España. ${ }^{19}$ Aún más, cada uno de estos tipos de narrativa se presenta paralelamente a través de composiciones poéticas escritas, que intercambian los participantes en cada una de las tertulias que se forman; composiciones poéticas que, alguno de ellos se encarga de leer en voz alta para que todos puedan tanto deleitarse como edificar su existencia mediante el mensaje difundido.

La oralidad toma forma en El desierto cuando se la enfoca en oposición a la literariedad que exhibe el mundo representado. Las dos, oralidad y literariedad se perfilan y se complementan entre sí; incluso, se las puede ver estrechamente interrelacionadas. En el nivel de la historia, la relación entre oralidad y literariedad es de mutua tensión creativa; tensión que tiene una doble dimensión histórica: por un lado, muestra cómo una sociedad letrada surge de una sociedad oral; por el otro, manifiesta lo que la literariedad puede llegar a significar cuando se superimpone sobre la oralidad característica del ser humano desde que nace y que gobierna muchos de los aspectos de la vida diaria.

En forma consciente al nivel del discurso, la tensión tiende en favor de la proposición de reemplazar la oralidad por una sofisticada literariedad; complicación que se manifiesta a través de las diferentes formas narrativas que se explicitan en el texto; como también, en las diferentes clases de composiciones poéticas que abundan a lo largo de El desierto, como son: los sonetos, los romances, las quintillas, las décimas, las silvas y las octavas reales. Pero a un nivel inconsciente, se manifiesta la presencia evidente de la oralidad circundante, que se cuela por los intersticios de la escritura. Intervalos que, a la vez que dejan vislumbrar el vigor que las sociedades orales del momento poseían, identifican un tipo de conciencia creada por la oralidad o expresable por ella (Feldman 47-65).

Para poder entender esta peculiaridad de la escritura de El desierto, deben tenerse presentes las características históricas del momento. Durante siglos, la transición de la oralidad a la literariedad en Europa fue bastante lenta; sólo hasta el humanismo renacentista se inventó la moderna forma de estudio e investigación que depende del libro, lo cual hizo que se desarrollaran las imprentas, promoviéndose la literariedad. Sin embrago hasta bien entrado el siglo XVIII, los textos escritos mostraban un pesado residuo de la oralidad, representado en el uso de epítetos, antítesis y palabras que expresaban lugares comunes (Ong 115).

Mientras esos cambios ocurrían en Europa, en los territorios hispanoamericanos durante la Colonia, la oralidad era el mundo hegemónico. Sus habitantes eran en su gran mayoría iletrados, para los estándares europeos. Sólo muy pocos sabían leer y escribir, pero incluso ésos que sabían, tenían muchas limitaciones porque vivían lejos de los centros culturales y de gobierno, carecían de imprentas y estaban rodeados por sociedades orales o por iletrados europeos. Dada esta situación, y a pesar del hecho de que en su escritura los autores hacían conscientes esfuerzos para seguir las normas gramaticales, retóricas y narrativas prevalentes y provenientes de Europa, la oralidad subvirtió en instancias sus intenciones. Esta compleja situación fue incomprensible para la época y marginó aún más la producción literaria colonial.

${ }^{19} \mathrm{El}$ narrador 1 [= Arsenio] es portavoz de distintivos tipos de narraciones que se presentan en la novela. Refiere relatos hagiográficos (San Bruno, San Benito); emplea y mezcla estructuras de las novelas bizantina, sentimental y de piratas (Arsenio-Casimira=Ascanio); expone relatos de misterio (Leoncio, Pedro Padilla), y hasta cuentecillos tradicionales, anécdotas, casos y episodios. 
Bakhtin, en sus estudios sobre el lenguaje, percibió claramente aspectos de esta realidad:

[L]a palabra es un acto doble. Está determinada igualmente por quien la emite y por aquél por quien se enuncia [...]. Cada una de las palabras expresa la relación con el otro. Yo me delimito verbalmente por el punto de vista del otro, pero finalmente por el punto de vista de la comunidad a la cual pertenezco (Bakhtin, Marxism 85-86).

Solís y Valenzuela, no sólo fue juez del Tribunal de la Inquisición, sino también sacerdote Capellán de pueblos de Indios. Es decir, además de tener la obligación de "poner escuela" en ellos en su propia lengua ${ }^{20}$ (enseñar la doctrina en la lengua que se hablara en esos pueblos), ${ }^{21}$ vivía rodeado tanto de sociedades aborígenes, que se basaban en la comunicación oral, como de iletrados europeos, cuyos pleitos y querellas con la Inquisición tenía que resolver. Al mismo tiempo, tanto como Notario del Santo Oficio de la Inquisición (Orjuela 54), como albacea y fideicomiso de diversas personas (Briceño Jáuregui 163), establecía y defendía causas ante los tribunales para que se respetaran las bases de los contratos establecidos, bien entre civiles o entre éstos y la Iglesia.

Constante lector, ${ }^{22}$ dona centenares de libros de su biblioteca personal en varias ocasiones al Monasterio de Monserrate, el cual ordena construir en Santa Fe (Briceño Jáuregui 168). Incluso, en su testamento se hallan mencionados sesenta y cinco textos, que todavía permanecían en su posesión (Briceño Jáuregui 439-461). Autor de ocho obras, tres de ellas de gran extensión, Solís y Valenzuela era un avezado escritor; pero sus conocimientos en el manejo de la escritura, es decir su literariedad, muestran en instancias filtraciones de la oralidad que lo rodeaba y en la que estaba insertado.

Ahora bien, las manifestaciones, que con más precisión se pueden señalar en $E l$ desierto, corresponden a características del proceso de conocimiento y memoria desarrollado por la culturas grafocéntricas; ya que, sobre los idiomas nativos la documentación es casi

${ }^{20}$ En el Concilio III de Lima (1583), se decidió que el adoctrinamiento se hiciera en lengua indígena; no se obligaba a los indígenas a aprender español. Esta situación persistió con algunas variaciones hasta 1770 , cuando Carlos III impuso la enseñanza en la lengua oficial, lo que "significó el fracaso de la doctrina de la Iglesia y el retroceso de las lenguas indígenas" (Alvar 18).

${ }^{21}$ Hacia 1620, el neogranadino Fray Bernardo de Lugo emprende la composición del "Arte y Confesionario en lengua chibcha". Era muy conocida su experiencia y larga práctica en el dominio y manejo de la lengua chibcha: "por el prolongado curso de afios que ha predicado el dicho evangelio en dicha lengua, no sólo en las doctrinas y curatos donde ha vivido, sino en las plazas y calles de esta ciudad de Santafé [...]. La orden Agustiniana no descuidó el estudio de las lenguas de los naturales [...]. Por disposición de la provincia de gracia no se podía presentar para doctrinero de ningún pueblo al religioso que antes no fuera examinado y aprobado en la lengua" (Romero 259-260).

22 "La erudición prodigiosa de don Pedro en términos de sabiduría bíblica, patrística, histórica, poética, filosófico-teórica, ascética, mística, literaria, moral, la ha bebido en multitud de libros de su propia biblioteca. Todo ello supone inagotables horas de estudio y consagración en la paz colonial de la Santafé que le correspondió vivir. Pero también tenacidad viril porque este libro [El desierto], voluminoso en páginas, fue caligrafiado por él mismo: y sabemos por lo menos de dos ejemplares más que figuran en el inventario de sus bienes al morir" (Briceño Jáuregui 420). 
inexistente ${ }^{23}$ para el área en que vivió Solís de Valenzuela. De esta forma, en numerosos fragmentos de su texto se observan las señales de la oralidad subversiva, que se manifiesta en el empleo de epítetos; ${ }^{24}$ en el uso de sintagmas aditivos marcados por cualquier tipo de conjunción; en la utilización de sintagmas y términos paralelos o antitéticos; en la redundancia de ideas; en la economía o ausencia total de enunciados abstractos; y en el empleo de conceptos situacionales, que acercan lo mencionado a lo conocido en el mundo diario. ${ }^{25}$

El fragmento inicial que abre $E l$ desierto, ejemplifica algunas de las manifestaciones de la oralidad en la escritura anteriormente mencionadas:

En 'animado' rayo, en 'veloz' bruto, hijo del viento Bóreas, de Dárdano en las yeguas engendrado, cuias 'azeradas' plantas no 'molestas' huellas eran, 'brebes' estampas sí a la arena, penetraba presuroso lo enhetrado de vna selva vn 'animoso' joben siguiendo a un cieruo, a quien sus 'irlandeses' pachanes $\$ ventores llevaban ya venzido; quando en vn vistoso, aunque 'pequeño monte' que era, o berruga de la tierra, o lunar que deleytosamente la adorna y compone, halló asylo en vna 'cavernosa' gruta o 'güeco' aposento, ciua lobreguez y estrechura atemorizó a sus enemigos, que en 'confussas' vozes indicaron a su dueño donde se ocultaba. El joben valeroso, nada tímido $\underline{o}$ cobarde, de vn 'lijero' salto occupó la tierra, y attando el bruto a las 'ojosas' ramas de vn 'silvestre' leño, enbrazando el 'bicorte' venablo, al entrar en aquella 'güeca' tumba, o rotura de la tierra ('propia' habitación, al parecer de algún sátyro o fauno), reparó en vnas letras que retalladas en vna piedra lisa, parezían 'fúnebre 'epitafio de quella 'triste' sepoltura. Mitigó la novedad el ardor colérico y enpezando a leer los mal 'formados' caracteres, por estar ya cubiertos del 'verde' belo de la peña, no juntaba sus dictiones. Hasta que el 'ardiente' desseo de penetrar el 'misterioso' secreto de aquel 'tosco' padrón, le obligó a limpiar la yerva que le cubría, $\$ a expensas de una 'brebe' diligencia descubrió estos versos: [...] (Solís y Valenzuela I: 11-12).

La abundancia de epítetos se observa claramente:

animado rayo
molestas huellas
irlandeses pachanes
güeco aposento
ojosas ramas
güeca tumba

\author{
veloz bruto \\ breves estampas \\ pequeño monte \\ confusas voces \\ silvestre leño \\ fúnebre epitafio
}

\author{
azeradas plantas \\ animoso joben \\ cavernosa gruta \\ lijero salto \\ bicorte venablo \\ triste sepoltura
}

\footnotetext{
${ }^{23}$ Esta lengua murió a comienzos del siglo XVIII. De ella subsisten apenas las referencias que quedaron plasmadas en las gramáticas y catecismos que emplearon los doctrineros para efectuar su labor de difusión del dogma. La primera gramática fue escrita por el fraile neogranadino Bernardo de Lugo (1619). Junto a éste, existe otro texto al parecer de mediados del siglo XVI, muestra de los muchos que debieron circular durante dos centurias; el cual se conservó en forma manuscrita hasta 1987 (González de Pérez 9).

24 "Las expresiones orales llevan una carga de epitetos y otras expresiones fijas que la alta literatura rechaza como redundantes a causa de su peso aditivo" (Ong 38).

25 "Las culturas orales tienden a usar conceptos situacionales en marcos operacionales de referencia que son mínimamente abstractos en el sentido en que permanecen cercanos al mundo cotidiano del ser humano" (Ong 49).
} 
verde belo

tosco padrón ardiente desseo

brebe diligencia

misterioso secreto

Este uso de epítetos convierte la prosa del escritor santafereño en un lugar de encuentro y lucha de fuerzas inmanentes de la naturaleza; en el que movimiento, tamaño, color, forma, efecto, son dinamismo agonísticos que producen una impresión más fuerte, más dramática, tanto al oyente como al lector. A su vez, esta presencia de los epítetos también señala, en Solís y Valenzuela, un asiduo manejo de fórmulas orales para difundir mensajes. En la oralidad el epíteto sirve como ayuda mnemotécnica para improvisar a medida que se desarrolla lo que se quiere transmitir (Havelock 22). El clérigo santafereño acostumbrado a predicar mediante pensamientos memorables, repetidos una y otra vez, no se da cuenta que lo diario, lo rutinario sube rápidamente a la superficie de su prosa; el rayo no es simplemente "rayo", sino "animado rayo", y así sucesivamente con el "bruto", el "leño", el "secreto", etc.

En la misma medida, el empleo de sintagmas aditivos marcados por conjunciones es muy evidente:

... quando en vn vistoso, aunque pequeño monte que era, o berruga de la tierra, o lunar que deleytosamente la adorna y compone, halló asylo en vna cavernosa gruta o gúeco aposento, cuia lobreguez y estrechura atemorizó a sus enemigos, que en confussas vozes indicaron a su dueño donde se ocultaba. El joben valeroso, nada tímido o cobarde, de vn lijero salto occupó la tierra, y attando el bruto a las ojosas ramas de vn silvestre leño, enbrazando el bicorte venablo, al entrar en aquella gúeca tumba, o rotura de la tierra (propia habitación, al parecer de algún sátyro o fauno).

Este tipo de estructura servía para proporcionar fluidez a las ideas; en cierto sentido acercaba el texto más a la pragmática de la época que tenía en cuenta la conveniencia del hablante. Debe tenerse presente que las culturas con un fuerte residuo de oralidad no ven la adición sintagmática como un problema, como bien lo afirma Ong (38), para ellos no era arcaica o retorcida, sino natural y normal.

Lo mismo sucede con el empleo de sintagmas y de términos paralelos y antitéticos, que produce una redundancia de ideas:

[no molestan huellas eran], [brebes estampas sí]

[pequeño monte] o [berruga de la tierra] o [lunar]

[adorna] y [compone]

[cavernosa gruta] o [güeco aposento]

[lobreguez] y [estrechura]

[tímido] o [cobarde]

[gúeca tumba] o [rotura de la tierra]

[sátyro] o [fauno]

Mediante la redundancia, la repetición del concepto o de la idea en otra forma, el hablante se asegura de que el oyente o lector comprende el mensaje. En la misma forma en que Solís y Valenzuela debía difundir y predicar la doctrina religiosa mediante repetición de palabras y expresiones, y tenía que adquirir la certeza de que la idea que quería transmitir 
era entendida, en lo escrito el religioso emplea términos y sintagmas paralelos para hacer comprensible y volver casi visual la misma idea.

En este fragmento también se observa el uso de conceptos situacionales que acercan lo mencionado a lo conocido en el mundo diario:

monte $=$ berruga de la tierra = lunar

cavernosa gruta $=$ güeco $=$ güeca tumba $=$ rotura de la tierra

Las estructuras de la oralidad que se hacen presentes con este tipo de conceptos situacionales sirven para traducir las ideas a términos más cercanos a lo cotidiano. Un elemento propio de la naturaleza se convierte en dos peculiaridades de lo humano: "monte" = "berruga", "lunar", etc. Este tipo de ordenación discursiva proporciona más dramatismo a lo descrito, para hacer el mensaje más perceptible y por tanto más fácil de grabar en la memoria.

Otra marca de la oralidad en este breve fragmento se manifiesta en la manera en que muestra a un personaje ejecutando continuos actos o sufriéndolos; pero hay una notable ausencia de enunciados abstractos; de ahí que la oralidad que se percibe, haga que lo relatado se presente a través de enunciados rítmicos narrativizados. Es decir, la sintaxis describe brevemente acciones y pasiones diferentes que producen una sensación de movimiento. Este hecho señala un hábito lingüístico de la oralidad, cuya función es, además de informar mediante elementos memorables, captar la atención del receptor entreteniéndolo. ${ }^{26}$

La unión de los epítetos, la repetición de la misma idea en otra forma o el opuesto de ella dotan el texto de un ritmo interno que se manifiesta en unidades de sentido expresadas con un número de palabras de más o menos igual cantidad. Este ritmo se percibe en la lectura oral del texto, y funciona como otra ayuda mnemotécnica que ayuda a recordar el mensaje que se quiere transmitir en la oralidad.

Un estudio sistemático de todo el texto de El desierto mostraría la manifestación de otras marcas de la oralidad presentes en la escritura de Solís y Valenzuela; las que unidas a características de la lengua chibcha, que tuvo que manejar para efectuar sus funciones de predicador, explicarían mejor contextualizando social e históricamente tanto al autor como a su escritura. No se pueden seguir considerando los diversos textos coloniales hispanoamericanos como defectuosos o faltos de originalidad. Si bien es cierto que la cultura hegemónica aportó e impuso inflexiblemente normas de escritura y modelos narrativos, la fuerte e irrefutable presencia de las culturas orales, aunada a otros factores geográficos, sociales y étnicos hizo que los escritores hispanoamericanos crearan un tipo de literatura que posee las peculiaridades del momento histórico en que se produjo. ${ }^{27}$

\footnotetext{
26 "El secreto de la oralidad radica no en el comportamiento que expresa el lenguaje cuando se intercambia, sino en la forma como se emplea el lenguaje para almacenar información en la memoria. Este lenguaje debe cumplir dos requisitos: debe ser a la vez rítmico y narrativizado. Debe describir acciones o pasiones, pero nunca principios o conceptos. Para dar un ejemplo, nunca dirá que la honestidad es la mejor conducta, sino que "un honesto hombre siempre prospera"' (Havelock 24). ${ }^{27}$ En sociedades en pequeña escala, como era la que circundaba al criollo Solís y Valenzuela, quien nunca salió de su natal Nueva Granada, "el pensamiento se emplea no sólo para ganar el sustento
} 
Las novelas coloniales hispanoamericanas, como tantos otros textos de la época, además de mostrar la dualidad entre realidad y ficción, exhiben el contacto agonístico entre culturas, la coexistencia de oralidad y literariedad; e incluso, son pruebas evidentes de que si en España se dictaban disposiciones para salvaguardar el bien del Imperio, en las colonias su interpretación no produjo lo que allá se esperaba. Los autores, insertos en culturas ajenas a las europeas, interpretaban y obedecían según las normas vigentes en el lugar en el que residían. Todas estas características se han visto como fallas de la cultura y por ende de la escritura hispanoamericana; pero ahora, gracias a las investigaciones que se están haciendo en diversas áreas de los estudios culturales, estos textos irreductibles hasta ahora a la cultura oficial y por lo tanto marginados por ella, se pueden comenzar a entender y estudiar como expresiones originales de una de las diversas facetas de la literatura hispanoamericana.

\section{APÉNDICE 1}

Estructura narrativa de
EL DESIERTO PRODIGIOSO Y EL PRODIGIO DEL DESIERTO
Pedro de Solís y Valenzuela

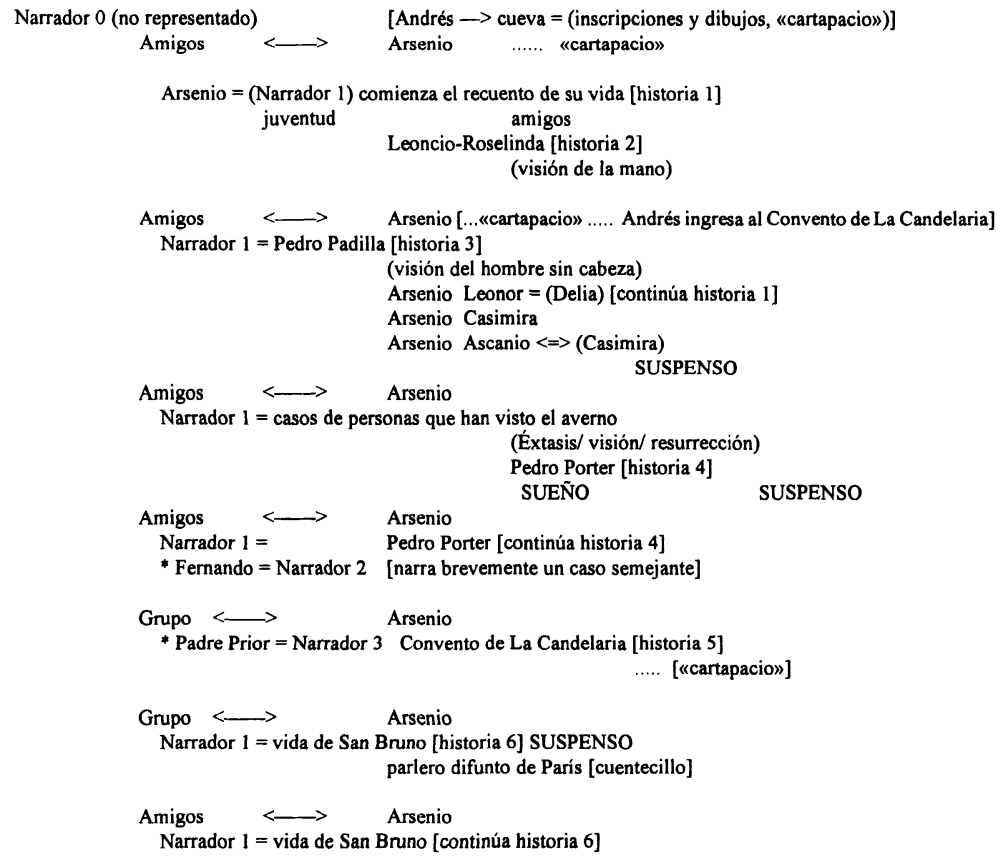

sino para dar apoyo a una estructura social. Sin instituciones sociales autónomas [...] el pensamiento diario debe compartir el peso de mantener conductas sociales correctas" (Denny 70). 


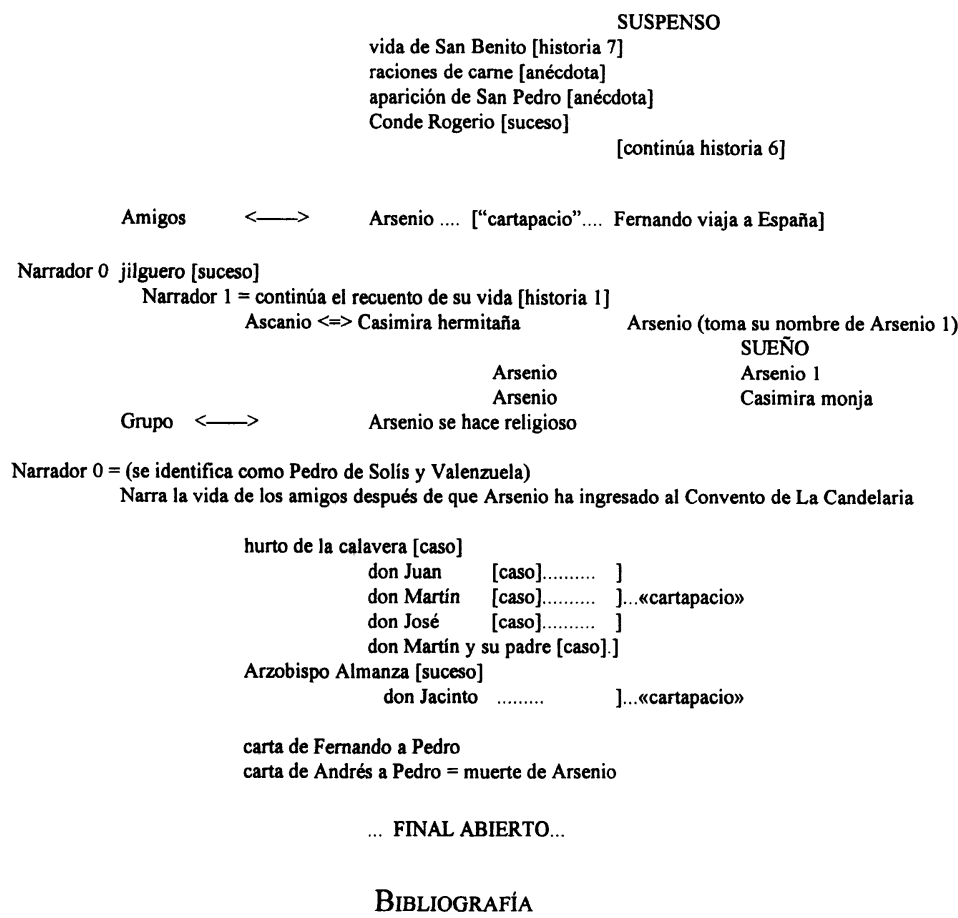

Alvar, Manuel. Resurrección de una lengua. Introducción a la edición facsimilar de la Gramática Chibcha del Padre Fray Bernardo de Lugo, editada en 1619. Madrid: Ediciones Cultura Hispánica del Centro Iberoamericano de Cooperación, 1978.

Anónimo. Diccionario y Gramática Chibcha. Manuscrito anónimo de la Biblioteca Nacional. María Stella González de Pérez, Transcripción y estudio histórico analítico. Bogotá: Instituto Caro y Cuervo, 1977.

Bakhtin, M. M. Marxism and the Philosophy of Language. New York: Seminar Press, 1973.

The Dialogic Imagination. Austin: University of Texas Press, 1981.

Boves Naves, María del Carmen. El diálogo: estudio pragmático, lingüistico y literario. Madrid: Gredos, 1992.

Briceño Jáuregui, Manuel. Estudio histórico-crítico de El desierto prodigioso y prodigio del desierto de don Pedro de Solís y Valenzuela. Bogotá: Instituto Caro y Cuervo, 1983.

Bruner, Jerome y Weisser, Susan. "The Invention of Self: Autobiography and its Forms". Literacy and Orality. David R. Olson y Nancy Torrance, editores. Cambridge: Cambridge University Press, 1992. 129-148.

Clark, Catherina and Holquist, Michael. Mikhail Bakhtin. Cambridge, Massachusetts: Harvard University Press, 1984. 
Denny, Peter J. "Rational thought in Oral Culture and Literate Descontextualization". Literacy and Orality. David R. Olson y Nancy Torrance, editores. Cambridge: Cambridge University Press, 1992. 66-89.

Digges, Diana y Joanne Rappaport. "Literacy, Orality and Ritual Practice in Highland Colombia". The Ethnography of Reading. Jonathan Boyarin, editor. Berkeley: University of California Press, 1992. 139-155.

Eagleton, Terry. Literary Theory. Minneapolis: University of Minnesota Press, 1983.

Feldman, Carol Fleisher. "Oral Metalanguage". Literacy and Orality. David R. Olson y

Nancy Torrance, editores. Cambridge: Cambridge University Press, 1992. 47-65.

Gellrich, Jesse M. The Idea of the Book in the Middle Ages. Language, Theory, Mythology, and Fiction. Ithaca and London: Cornell University Press, 1985.

González de Pérez, María Stella. "Breve estudio histórico-analítico". Diccionario y Gramática Chibcha. Manuscrito anónimo de la Biblioteca Nacional de Colombia. Bogotá: Intituto Caro y Cuervo, 1987. 3-63.

Goody, Jack. The Domestication of the Savage Mind. Cambridge: University Press, 1977.

The Interface between the Written and the Oral. Cambridge: University Press, 1987.

Havellock, Eric, "The Oral-Literate Equation: A Formula for the Modern Mind". Literacy and Orality. David R. Olson y Nancy Torrance, editores. Cambridge: Cambridge University Press, 1992. 11-27.

Lienhard, Martin. La voz y su huella: Escritura y conflicto étnico social en América Latina (1492-1988). La Habana: Casa de las Américas, 1990.

López Grijera, Luisa. "En torno a la descripción en la prosa de los Siglos de Oro". Homenaje a José Manuel Blecua. Madrid: Gredos, 1983. 347-357.

Lugo, Bernardo. Gramática en la lengva general del Nuevo Reyno, llamada mosca. 1619. (Facsimilar) Madrid: Ediciones Cultura Hispánica del Centro Iberoamericano de Cooperación, 1978.

Mignolo, Walter. "Diálogo y conversación”. La semiótica del diálogo. Amsterdam: Rodopi, 1987. 3-26.

Olson, David R. y Nancy Torrance (editores). Literacy and Orality. Cambridge: University Press, 1991.

Ong, Walter. Orality and Literacy: the Technologizing of the Word. London and New York: Methuen, 1982.

Orjuela, Héctor $\mathrm{H}$. 'El desierto prodigioso y prodigio del desierto' de Pedro de Solís y Valenzuela: primera novela hispanoamericana. Instituto Caro y Cuervo, Bogotá, 1984.

Prieto, Antonio. "La prosa en el siglo XVI". Historia de la literatura española. I: Edad Media y Renacimiento. José María Diez Borque (Coordinador). Madrid: Guadiana, 1974. 491-563.

Romero, Mario Germán. Fray Juan de los Barrios y la evangelización del Nuevo Reino de Granada. Bogotá: Academia Colombiana de Historia, 1960.

Solís y Valenzuela, Pedro de. El desierto prodigioso y prodigio del desierto. Edición de Rubén Pérez Patiño, Introducción estudio y notas de Jorge Páramo Pomareda, Manuel 
Briceño Jáuregui, Rubén Pérez Patiño. Bogotá: Instituto Caro y Cuervo, I: 1977, II: 1984.

Vansina, Jan. Oral Tradition as History. Wisconsin: The University of Wisconsin Press, 1985.

Varela, Julia. Modos de educación en la España de la Contrarreforma. Madrid: Las Ediciones de la Piqueta, 1983.

Weinrich, Harald. Estructura y función de los tiempos en el lenguaje. Madrid: Gredos, 1974. 